This item was submitted to Loughborough's Research Repository by the author.

Items in Figshare are protected by copyright, with all rights reserved, unless otherwise indicated.

\title{
Lived experiences of offshoring : an examination of UK and Indian financial service employees' accounts of themselves and one another
}

PLEASE CITE THE PUBLISHED VERSION

PUBLISHER

Sage / @ The Tavistock Institute

VERSION

AM (Accepted Manuscript)

LICENCE

CC BY-NC-ND 4.0

\section{REPOSITORY RECORD}

Cohen, Laurie, and Amal El-Sawad. 2019. "Lived Experiences of Offshoring : An Examination of UK and Indian Financial Service Employees' Accounts of Themselves and One Another". figshare.

https://hdl.handle.net/2134/4109. 
This item was submitted to Loughborough's Institutional Repository (https://dspace.lboro.ac.uk/) by the author and is made available under the following Creative Commons Licence conditions.

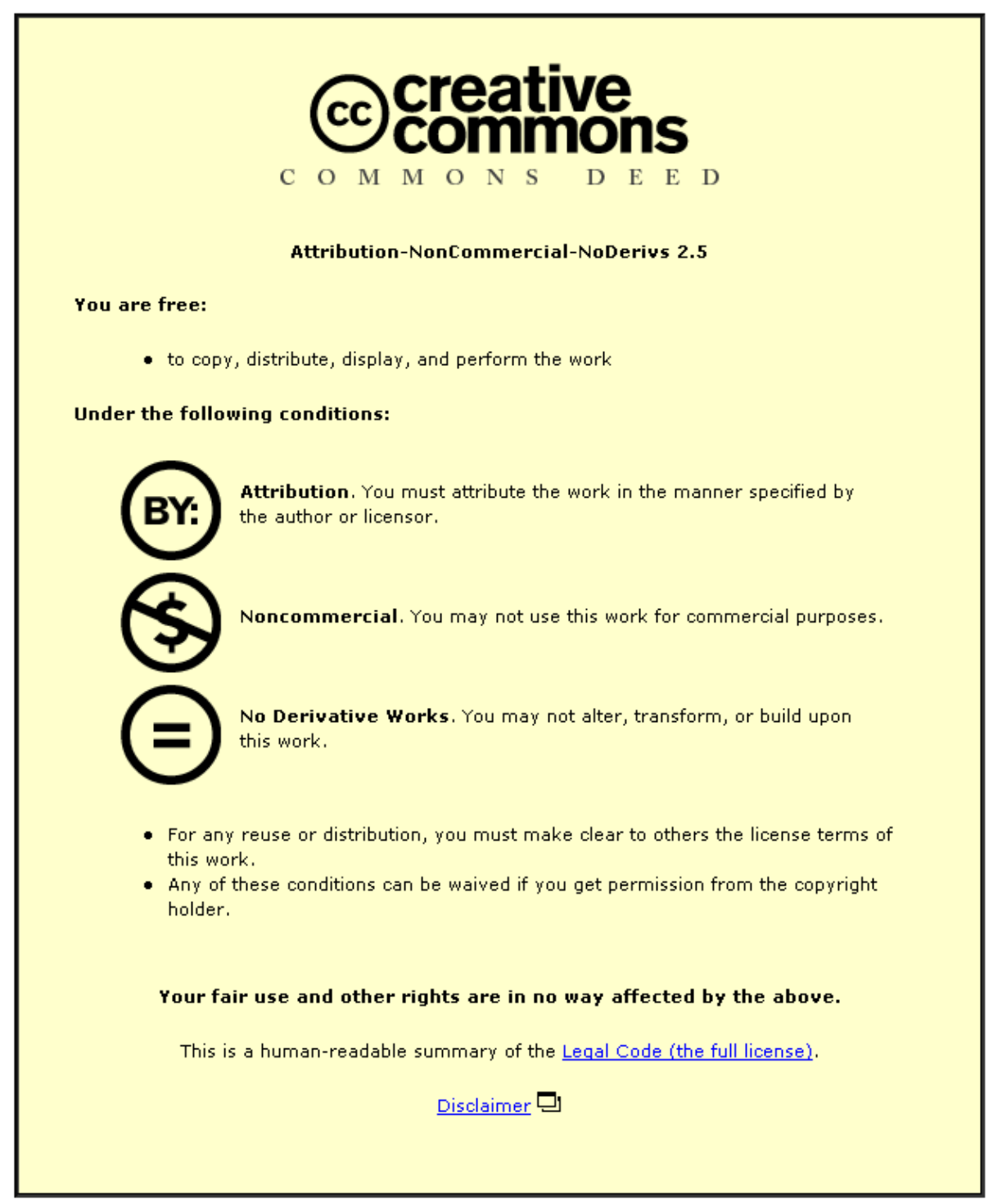

For the full text of this licence, please go to: http://creativecommons.org/licenses/by-nc-nd/2.5/ 


\title{
Lived experiences of offshoring: an examination of UK and Indian financial service employees' accounts of themselves and one another
}

\section{Laurie Cohen and Amal El-Sawad}

\begin{abstract}
This article is about employees' lived experiences of offshoring. Focusing on the accounts of individuals in a financial services company operating in the UK and Mumbai, India, it examines the ways in which respondents constructed and positioned themselves in relation to one another in the stories they told. We argue that in their accounts our respondents mobilized discourses of culture and cultural difference to describe and justify this positioning, with particular reference to 'the language barrier', work ethics and notions of competence. We draw three broad conclusions. The first is empirical and concerns the benefits of in-depth case study research for developing understandings of this emerging sector. The second conclusion relates to respondents' use of cultural ascriptions to justify certain existing patterns of behaviour and to foreclose discussion of alternatives. The third conclusion highlights the deep sense of ambivalence that permeates our dataset, proposing that within this ambivalence lie possibilities for resistance and change.
\end{abstract}

This paper is about employees' lived experiences of offshoring. Focusing on the accounts of individuals in a financial services company operating in three centres in the United Kingdom and one in Mumbai, India, it examines the ways in which Indian and UK workers account for one another, and considers these understandings for organizational practice. In the last five years the growth of business outsourcing and offshoring has generated fierce debate. On a macro level, while some commentators have described such arrangements as providing both source and destination countries with opportunities for prosperity, flexibility, security and freedom (Friedman, 2005), others see India, China etc. simply as providers of cheap labour, and this form of modernisation as ultimately leading to even greater inequality and deprivation (Mishra, 2006). With regard to India in particular, with some notable exceptions (eg, Mirchandani, 2004, 2005; McMillan, 2006) commentators are similarly divided, with arguments that the technology enabled sector is offering high wages and unprecedented career and life prospects to aspirational young people (NASSCOM; Dossani \& Kenney, 2003) set against a view of Indian customer service workers as 'cyber coolies', 'insecure' and 'vulnerable' casualities of the new economic order (Ramesh, 2004).

While important contextually, our paper does not aim to take a position in this highly polarized debate. Rather, our interest here is in employees' lived experiences of these new forms of organization. The literature on customer service sectors highlights relationships with customers as central to employees' experiences of work (Korczynski, 2002; Mirchandani, 2005). However, in our data it was the dynamics between UK and Indian employees that emerged as a defining feature of this transnational setting. In this paper we interrogate the ways in which respondents constructed and positioned themselves in relation to one another in the stories they told. We argue that in their accounts our respondents mobilised discourses of 'culture' and especially of 'cultural difference' to describe and justify this positioning, most specifically with respect to language issues, work ethics and their implications for organizational practice, and notions of competence. We suggest that such data provide rich insights into how work is made sense of, legitimated and enacted in these putative organizational forms.

A distinguishing feature of our study is the structure of our case study organization. As Taylor and Bain (2003) have explained, outsourcing and offshoring are generic 
terms, used in diverse, sometimes overlapping ways, to denote a whole range of organizational arrangements from contracting out to a third party based overseas (described in India as 'business process outsourcing', or BPO), to the wholly owned subsidiary (in India termed the 'captive') (see also Mitter, 2000 and Dossani \& Kenney, 2003). The organization we studied is a captive, which means that although the Indian operation has its own management structure, UK and Indian employees work alongside one another and are all considered to be part of the same, highly reputed and long-standing UK financial services company. Whereas the BPO sector is based on short-term, transactional client/service provider relationships, in a captive the relationships between India and the UK are much more complex, with business processes wholly based in one site, with others operating across sites. This matrix structure creates spaces for wide-ranging interaction and the development of multifaceted relationships between the UK and Indian staff.

Turning to the structure of the paper, following this introduction we will consider key debates and perspectives in the literature on offshored customer service work, then focus on the Indian context in particular and the ways in which this has been written about in the West, as well as in the Indian popular and academic press. We then turn to our study, briefly describing the case study organization and our research design. The empirical discussion examines respondents' ascriptions of culture and cultural difference with respect to three permeating themes: the 'language barrier', work ethics and organizational practices, and notions of competence. In the discussion we draw three broad conclusions. The first is empirical and concerns the benefits of indepth case study research for developing understandings of this emerging sector. The second conclusion relates to respondents' use of cultural ascriptions to justify certain existing patterns of behaviour, and to foreclose discussion of alternatives. The third conclusion highlights the deep sense of ambivalence that permeates our dataset, proposing that within this ambivalence lie possibilities for resistance and change.

\section{Perspectives on Indian offshoring: globalisation and the transformation of identity}

Informed by a significant body of research into call centres more generally (Batt \& Moynihan, 2002; Kinnie, Purcell \& Hutchinson, 2000; Frenkel, Korczynski, Shire \& Tam, 1999; Korczynski, 2002; Houlihan, 2002) an increasing number of empirical studies into the labour processes involved in Indian business process outsourcing is appearing in both western and Indian academic journals (Taylor \& Bain, 2005; Mirchandani, 2004, 2005; Ramesh, 2004; McMillan, 2006). Discussing motives and triggers for offshoring particular business processes to developing countries, commentators agree that there are two key, inter-related reasons: cost savings and the promise of 'acceptable or better' quality (Dossani \& Kenney, 2003; Taylor \& Bain, 2005; Walsh \& Deery, 2006). Here the Indian labour market, with its high levels of English language competence, expertise in mathematics, science and engineering, and its unique demographic profile (with over $50 \%$ of the population being under 25 years of age) (NASSCOM, 2006) is seen as offering particular advantages in terms of levels of skill, knowledge, aptitude and attitude (Walsh \& Deery, 2006).

This literature depicts a stark distinction between this emerging class of workers and those in more traditional Indian employment sectors. Likewise, it is in striking contrast to the three UK labour markets in which our case study organization operates, which are broadly characterised by lower levels of educational attainment, older age profiles and concomitant differences in perceptions of opportunity and aspiration. Given our interest in exploring relationships between UK and Indian employees, and 
especially the ways in which they make sense of one another, these differences in labour market characteristics are highly pertinent.

In their study of the call centre industry in India, Taylor and Bain (2005) sought to challenge assumptions that in the context of ever increasing global connectivity, the migration of business activities to India can be seen as a 'seamless' process, facilitated by communication technologies and ultimately leading to significant reductions in cost. Based on data generated in interviews with senior managers and questionnaires in call centres in Delhi, Bangalore and Mumbai, Taylor and Bain argue that India has reproduced some of the most problematic aspects of western call centre labour processes, in uniquely Indian ways. While an examination of the labour process is not our specific interest in this paper, these studies do raise some significant issues that we need to consider. First, the call centres in which Taylor and Bain based their work appear to be BPOs rather than captive units. However, in the captive unit, such as our case study organization, the labour process might look quite different. For our purposes it is important to consider how employees see the Mumbai operation compared to the other three customer service centres. Whether Mumbai is considered the site for the most routinized work, or as a more equal partner involved in higher discretion processes alongside UK operations, could have significant implications for employees' ideas about themselves and their overseas colleagues.

Second, although it is not their central focus, Taylor and Bain touch on the cultural dimensions of offshoring, and particularly the implications of such practices for individuals' sense of cultural identity, a theme which has likewise generated considerable debate amongst Indian academics. Somewhat paradoxically, given their elite status in India and greater cultural capital in relation to their UK counterparts, Ramesh (2004) describes the workers in India's new economy as 'cyber coolies: 'insecure' and 'vulnerable' casualties of the new economic order. He argues that the precariousness of the new economy is related most fundamentally to the increasing instability of workers' sense of who they are: 'Agents, especially those who work on voice processes, are forced to live as Indian by day and westerner after sundown' (2004: 11). Thus the workers in Ramesh's analysis appear to lead a double life - an 'authentic', Indian, daytime life, and a pretend, Western, night-time one. Whilst dramatic and compelling, this argument strikes of an essentialism which we suggest might serve to gloss over more complex processes of identity construction. It connotes a sense of Indian culture which is coherent and stable, and fundamentally distinct from the West. In this way, Ramesh's analysis appear to ignore aspects of Western culture which have long historical roots and are deeply embedded in, and inextricable from contemporary Indian society (Chakrabarty, 2005). Furthermore, within this vision the individual appears to have no free will as to which of these identities she or he takes on.

Ramesh's perspective is echoed by McMillan (2006), also writing in India's Economic and Political Weekly. Although she situates her study within post-colonial debates rather than labour process theory, McMillan highlights many of the empirical issues raised by Taylor and Bain. Reminiscent of Ramesh's 'cyber coolie', she describes Indian call centre workers as 'the global proletariat', citing in particular the routinization of work, the emotional labour that dealing with customers inevitably involves, and most particularly the 'cultural transformations' that Indian agents need to undergo to get their jobs done:

For call centre employees, to live and breathe the cultural contexts of their clientele, names are changed from Indian to western ones (particularly for 
US-based clients) and fictional personal profiles are developed with residential roots in some prominent city in the US... (2006: 238).

On one hand, then, McMillan appears to draw on the same essentialist arguments as Ramesh. In her words:

The call centres then stand as strong symbols of a neo-colonialist environment, where labourers need to enter into the cultural contexts of their employers and clientele based in the UK, UK, Germany or the Netherlands, as the case may be, and using their knowledge of the range of customer services available to the client, converse fluently, stripping away as much as possible, indicators of their local, Indian contexts.

Here again, we would take issue with the implication that these new, Western forms of organization seemed to have landed on a cultural landscape that had previously been untouched by Western influences. However, notable in McMillan's data are employees' diverse responses to these normative imperatives. While some agents acknowledged the impact of such practices on their sense of cultural identity, others talked about it as a necessary requirement of the job, and still others appeared to really enjoy it - describing it as part of the fun of working in a modern organization.

Taking issue with the argument that globalisation is heralding a kind of economic and cultural homogenization (Schiller, 1991) in Indian's metropolitan areas, McMillan draws on the work of Homi Bhabha, and particularly his concept of 'hybridisation', to describe the increasing interplay between local and global meaning systems in third world cities (see also Mirchandani, 2004), and the destabilisation and transformation of identity which is at the heart of such 'creolisation'. In Bhabha's words: 'This interstitial passage between fixed identifications opens up the possibility of a cultural hybridity that entertains difference without an assumed or imposed hierarchy' (1994: 4). However, McMillan criticizes what she sees as Bhabha's depoliticised perspective, arguing that embedded within the hybrid is a power struggle between what is seen as the global, and what is seen as the local. In the call centre context, she maintains that while employees may maintain a powerful sense of being Indian, there is at the same time an awareness of the 'superior economic value of the global personal' (237). We do not share McMillan's reading of Bhabha's The Location of Culture. Although Bhabha rejects the idea of cultural processes as 'fixed', and creates space for challenge and, potentially, transformation, this does not mean that his analysis is apolitical. On the contrary, we would argue that his notions of ambivalence and mimicry in particular certainly do take account of social relations, while acknowledging their fluidity and potential for resistance and change. Indeed, we suggest that his concept of ambivalence in particular could be a powerful tool for moving beyond the kind of reductionist views noted above, highlighting the significance of culture as a site of hegemonic struggle.

Looking more specifically at the processes through which identities and relationships are constructed and enacted, the analysis put forward by Gopal, Willis and Gopal (2003) is potentially useful. In their view, globalisation is the most recent manifestation of colonialism based, as earlier versions of the same phenomenon, on a contradiction between practices that are seen as 'good for' the colonised, but which ultimately compromise its integrity. Focusing on the role of information and communication technologies (ICTs) in processes of globalisation, in contast to many commentators both in the west and in India, Gopal and his colleagues argue that far from delivering greater freedoms and opportunities to developing economies, such technologies could ultimately work to sustain existing patterns of domination and subordination. Gopal, Willis and Gopal identify three key characteristics of ICTs (and 
of colonialism): standardization, invisibility and conditioning effects. It is the latter two that most concern us here. Whereas Gopal and his colleagues use the idea of invisibility in relation to ITC processes, in the context of our study, it is more illuminating to apply it to people. In the BPO sector it could be argued that Indians are effectively rendered invisible through taking on Western pseudonyms, accents and home addresses. However, where the Indian site is an acknowledged partner in the organization, questions of exposure and invisibility are potentially more subtle, and their consequences more complex. Also, it is worth noting that much of the literature assumes the US, not the UK as the source country. In UK, relationships with India clearly have a different history, movement between the countries is more commonplace and Indian names are very familiar, thus we mustn't assume that these processes will be played out in the same ways.

The third feature identified by Gopal, Willis and Gopal is conditioning effects. Central here is the hegemonic process through which particular ways of working, thinking and being, and the systems of values embedded within them, come to be experienced, not as social constructs, but as social facts - as 'commonsense' (Gramsci, 1971). Gopal and his colleagues identify the development of a group of 'translators' between the colonisers and the colonised as a key aspect of the machinery of colonialism. They quote from a speech made by Lord Thomas Macaulay (frequently cited by postcolonial writers), Legal Member of the Council of Indian Education in 1785: 'We must at present do our best to form a class of interpreters between us and the natives we govern; a class of persons Indian in blood and colour but English in tastes, in opinions, in morals and in intellect' (1972: 249). Over 200 years later, this sounds very much like the description of young people described in reports of offshoring (Taylor \& Bain, 2005; Ramesh, 2004; Deb, 2004; Mirchandani, 2005; McMillan, 2006). For us, an important issue here is the extent to which conditioning effects, and notions of 'commonsense' are apparent in employees' accounts of themselves and one another, and with what implications.

\section{Background to the study and research design}

This paper is based on ethnographic, case study research (Hammersley \& Atkinson, 1995; Bryman, 2004) into the customer service division of a multi-national financial services company. As noted at the outset of the paper, the company was chosen because as a 'captive', it represents a particular type of offshoring which thus far has received little research attention, but which offers a fascinating arena for studying the lived experience of employees in both source and destination countries. The organization operates three customer service centres in the United Kingdom (England, Scotland and Northern Ireland) and one in Mumbai. In terms of structure, the captive Indian unit is a wholly-owned subsidiary of the parent company. Indian employees work in the same regulatory environment as their UK counterparts, within the same overall structural context, and are managed with reference to very similar human resources policies and practices, opportunities and constraints, with minor differences reflecting aspects of the local environment. Telephone calls between the continents are made as if they are local and ICT systems enable customer service representatives in two different continents to work off what is effectively the same computer screen. In contrast to the image depicted in some of the literature, Indian employees are not expected to hide their Indian-ness by taking on pseudonyms or false addresses. It is also significant that although the Mumbai site does operate on source country time, because this is the UK rather than the US, employees do not work through the night. Notably, whereas turnover rates within the BPO sector can be upwards of $65 \%$ (sometimes reaching as high as 80\%), here in Spring 2006 it was calculated at $25 \%$. 
From the very outset of our research it became apparent that the social status and prestige that Indian employees seemed to derive from working in this organization were very different from that of their UK counterparts. Nearly all of our Mumbai respondents spoke of the pride they felt in being associated with this company, a 'brand' which to them meant stability, security, success, longevity, tradition and excellence, and they took great pleasure in the fact that their parents and friends thought highly of the company and its reputation. Indeed, we were struck by how much this prestige, and particularly the views of family and close friends, mattered to our Indian respondents, as it was not something that we had come across before. This is not to say that UK employees were not proud of their organization, nor are we suggesting that UK respondents were uniform in their feelings in this respect (on the contrary, during the course of our research we became acutely aware of some important differences between these sites, though this is a point which is beyond the scope of this paper). Rather the point we are making is that in contrast to India, it appears that in the in the UK working as a customer service representative in an organization like this is not seen as a high status occupation.

Our fieldwork, based in all four customer service centres, was conducted between Autumn 2004 and Spring 2006 and had several components. The bulk of the data was generated through semi-structured interviews (Kvale, 1996) with employees, ranging from entry level agents through consultants, team leaders and coaches (in Mumbai termed process leaders), middle managers and up to the Director of Customer Services for the whole organization, and the Managing Director of the Mumbai subsidiary. In total we conducted 59 interviews: nine in England, 11 in Scotland, nine in Northern Ireland and 30 in Mumbai. ${ }^{1}$ Respondents were split evenly in terms of gender. The majority of the UK respondents were between 30 and 40 years old, while the majority of the Indian cohort was between 20 and 30 . The senior managers were in their late 30's and 40's. Significantly, all of the Indian respondents had completed first degrees and several had Masters, while the majority of UK respondents had no higher educational qualifications. Many respondents had acquired professional qualifications during their time at the organization.

Regarding the work itself, the agents and consultants in our dataset were all involved in servicing customer accounts on a range of products including life insurance, pensions and annuities. New products were frequently being rolled out, and respondents spoke at some length about who got selected to work on these. Furthermore, whilst some respondents focused on one particular product or process, others were cross-trained to service several at once. This was generally seen as a good career move, and was something people wanted to given an opportunity to do. Agents and representatives dealt with a wide range of customer enquiries, from the provision of basic account information through to more complex processes like claims, complaints and customer retention. Back office and customer-facing processes were situated in the UK and Mumbai, and in each country we talked to employees involved in both. As noted at the outset, while some processes were wholly based in one site or another, others (such as customer retention) spanned sites. Notably, there were two sorts of customers: account holders and independent financial advisors. Of these, the IFAs were seen as most difficult, and also as having most status. It was explained to us that because IFAs frequently complained, and on many occasions had refused to speak to Indians, the company had decided to handle them exclusively in the UK. However, because IFAs tended to present the most complex and interesting problems, and were at the same time seen as the most

\footnotetext{
${ }^{1}$ The discrepancy here was due to resourcing. The first part of the India-based work was funded by the British Academy (which is why were able to conduct more interviews there). The second phase was supported by the Economic and Social Research Council.
} 
prestigious customers, some Indian employees were unhappy about being sidelined in this respect. This led to some interesting political manoeuvring which will be touched on in the data section.

Interviews focused on employees' experiences and perceptions of work in this organization, factors which enabled them and constrained them in their career development, the impact of factors such as gender/class/caste, faith, family etc on their progress in work and career, and aspirations for the future. While we did not ask specific questions about culture, in both UK and Indian accounts this turned out to be a central theme in how people accounted for work and career in this organizational setting. Interviews were recorded, transcribed verbatim and template analyses (King, 2004) were managed through NVivo software. In addition to these interviews, we generated extensive data through non-participant and participant observation. In all four sites we were given rooms to work, with open access to the open-plan offices of the agents and consultants. We had lunch in the employee canteens, joined employees for coffee and tea in the staff rooms. We also held feedback sessions with senior and middle managers at all four sites. Managers right across the organization attended the three UK events, though in Mumbai only local managers were able to be involved. In India we were also able to observe a training session. During our time in Mumbai we stayed in a nearby hotel which visitors and people on secondment to the centre regularly use. This meant that we spent social time with company staff at the hotel, and travelled between the hotel and the offices with them in the company cars. We used feedback workshops and seminars in all four sites as opportunities for further data collection.

Above we noted that our Mumbai work was held in two stages. The first was when we conducted most of the interviews and the most extensive observation. A year later we went back for a seminar which we jointly ran with the organization.

Academics from Delhi, Calcutta, Mumbai and the UK attended and participated, and presentations were also made by two of the organization's senior managers. The delivery of this seminar depended on close collaboration with contacts in the organization. This process, together with the seminar itself, was a fabulous opportunity for us to engage in participant observation, providing insights into organizational processes and practices that otherwise might not have been available. Fieldnotes were written up throughout the observations and later transcribed.

\section{Data: 'there's culture for a start - it's really completely different'}

While the central relationship in McMillan's (2006) analysis of identity transformation (and indeed in much of the literature on the customer service sector) is between call centre customer service representatives and their customers, in this transnational organization what appeared to be more salient to employees was how employees accounted for one another. As mentioned, as a captive unit the Mumbai site was an integral part of the case study company. Thus business processes, HR policies and practices, and even people themselves moved backwards and forwards between the UK and Mumbai. In this section we explore how notions of oneself and the other are constituted in what McMillan describes as this interconnected context, and consider ramifications for organizational practices and processes.

Permeating respondents' were references to 'culture', and most especially to 'cultural difference'. To many UK respondents, cultural difference was described as the most significant stumbling block to day-to-day operations, and to the phenomenon of business process migration more generally. While Indian respondents were less apt to make these attributions (though did in relation to the work ethic, as will be discussed), they were very much aware of their salience within organizational discourse, and oriented to these understandings in describing themselves, their 
colleagues and their dynamic interplay. Interestingly, we noted that at times these references were used as a sort of 'last word'. That is, having explained some organizational feature or problem in these terms respondents would stop talking, as if no further elaboration was needed. Several times when we asked people to explain what they meant, they couldn't really do so. Twice respondents considered and changed their minds, having decided that maybe the problem wasn't cultural difference after all. This back-tracking is fascinating in its own right and will be noted in the analysis. Apart from these instances of back-pedalling, though, our analysis revealed that respondents' attributions of culture and cultural difference were broadly related to three permeating issues: the 'language barrier', work ethics and their implications for organizational practice, and notions of competence. In the following sections we examine these themes.

\section{The 'language barrier'}

Amongst many UK customer service agents and representatives (most notably those who had not spent time at the Mumbai site) 'cultural difference', particularly in the form of 'the language barrier' was highlighted as one of the most problematic aspects of offshoring. For some the difficulty was about not understanding or misunderstanding, leading to problems in getting the job done, and especially the possibility of mistakes. For others, though, it was not a question of comprehension, but a more general sense of discomfort and unease with how their Indian colleagues expressed themselves. As an English representative explained:

The people in Mumbai speak very, very good English. Well, they speak better English than us really ... You know, you get the dictionary coming out and the grammar coming out that the normal person on the street in the UK wouldn't necessarily use which can sometimes be a bit artificial.

Because they had been educated in English medium schools and selected partly on the basis of their language skills, the organization's expectations with regard to additional language tuition were minimal. Although Indian respondents did not find communication to be a problem, they were well aware of their UK colleagues' perception of the 'language barrier', and so did everything they could to overcome it, taking advantage of every opportunity for further language and cultural training even when it was not required by the company. As an English manager with responsibility for training and development explained:

When we were doing this [language and cultural training] originally Mumbai wanted particular things, protocols, around accent and nuance and so on. Now I didn't want that because really why should we be auditing the Mumbai guys on a different level from us. You know, we've got accents, and they do in Scotland and they can be bloody difficult to understand, but this was something that Mumbai particularly wanted. They wanted it big time. They still do, yeah.

This was echoed by Indian customer service agents who saw this extra training as a way of meeting 'the expectations of counterparts and colleagues in the UK' in order to 'bridge the credibility gap' - a seemingly inevitable obstacle in the offshoring process. The aim in refining their language in this way was to blend in and ultimately, to appear 'less Indian'. What's fascinating here though is that it is not the UK operation imposing this imperative on the Mumbai site, but something that is being driven by Mumbai employees themselves. In addition to conditioning effects, Gopal and his colleagues (2003) argue that invisibility is a characteristic of colonialism. Here we have an example of both. Through extensive training, the hope is that Mumbai employees can make their foreign-ness disappear, a goal which in this 
context is seen as normal and appropriate. However it is important to look at these comments not simply as conforming to the expectations of this western organization, but also in the wider Indian educational and social context, where speaking perfect English continues to be a potent symbol of success.

Attributions of 'the language barrier' were made much more frequently by UK than by Indian respondents. Looking closely at the UK data, it became clear that such attributions frequently had little if anything to do with language. Rather, this appeared to be used as a short-hand for something else. For example, in the following quote a Scottish customer service representative was talking about the problems of cultural difference in relation to language, then in the course of his explanation realised that he'd got it wrong:

It's just the language barrier that's the problem... it wasn't just the language barrier. It was, these people are taking our jobs.

Illustrating the kind of back-tracking we noted in the introduction to this section, here it appears that that the 'language barrier' was being used as an excuse. Language wasn't the problem; rather, the problem was the perception that UK employees were losing their jobs to Indians. On one hand, we might argue that powerless in the face of the corporate decision to migrate, by redirecting their resentment towards their Mumbai colleagues themselves, UK staff regained a feeling of being in control. In construing their particular form of expression and use of English as the standard against which their Indian colleagues are judged, they achieve a sense of superiority over their Indian counterparts, thus possibly offsetting some of the feelings of insecurity and vulnerability generated by the organizational-level change.

Alternatively, it could be that while expressing their anger about this strategic change was not seen as legitimate (one of the things employees are judged on is demonstrating enthusiasm for change), complaining about the 'language barrier' was acceptable. Used this way, it serves to foreclose further discussion, thus obviating the need for deeper, more critical reflection, and crucially, not rocking the corporate boat.

Work ethics and organizational practices

Regarding attitudes towards work, there was a consensus across the dataset that Indian and British employees embraced very different work ethics. As a manager from Scotland explained:

I think the whole work ethic is fantastic in India. I think if I need something done, someone in India will do it. In the UK you've got to jump through hoops sometimes to get people to accept changes to processes, changes to procedures. They can see it as a bit of a hassle whereas in India they're enthusiastic about it because it's something different and they're so willing to demonstrate that they can do things well. I mean if we're looking at introducing new retention triggers where people call in the call centres need to identify retention opportunities, I know we can get all the training material all done, roll it out in India, great, they'll really embrace it and think 'this is great' and get on with it. In the UK, we'll have to negotiate with them, they'll push back the timescales... so there'll be a million reasons why 'oh, it can't be done today' type thing.

This idea is echoed in the following quote in which a more junior employee describes the very different role that work plays in her Indian colleagues' life than in her own: 
But I think it's a whole different culture over there. The whole work ethic from Mumbai is completely different. They love their work. They take their whole families into work. Your family, you maybe take 20 members of your family in to see where you work and that's accepted. ... They're there all night because they love going to work.

This belief that Indian and UK employees held very different attitudes to work was likewise endorsed by the majority of Indian respondents. For example, several agents noted that while their UK counterparts worked to strict timings, Indian employees regularly (and indeed willingly) stay late and work until the job is done:

Work-wise there's a very rigid timing they follow [in the UK]. It's 9 to 5. 'I'm not going to sit a minute above 5 o'clock', which is not the case over here. If you look at anyone over here, people happily stretch the hours they have, happily knowing they're not going to get anything out of it, In spite of that, they're happily doing this.

These contrasting work ethics seemed to be related to what were depicted in the data as very different relationships and commitments to the wider social contexts in which UK (most especially English and Scottish) and Indian respondents were situated. There was a strong sense throughout the Indian data that although respondents were working in a UK organization, to UK schedules and protocols, and even trying to make their Indian-ness disappear when they spoke to UK colleagues and customers, they were not somehow sacrificing one identity for another, and most certainly had no wish to move to the UK (although many relished the opportunity of a secondment, as did their UK counterparts to Mumbai). Rather, they saw India as being in the midst of massive growth and development, and themselves as an integral part of that process. Although they wanted to sound British, they expressed no wish to be British. The British respondents conveyed less confidence in this sense. Whereas the Indians perceived Britain as providing opportunities, though with significant ambivalence with regard to issues of power and status, in general the British were far more sceptical about their Indian counterparts, and certainly in the early stages saw them as threatening.

It was significant that where Indian respondents often spoke of their wider social (typically family and economic) contexts, and talked with excitement of their role in India's development, there was little sense of this engagement in the UK data. With the notable exception of several Northern Irish respondents (an interesting finding in its own right that unfortunately extends beyond the scope of this paper), people did not express any particular connection with their local communities or society more generally. In this respect we were particularly struck by three young Scottish men, better educated than many of their peers, who appeared to have little sense of affiliation to any social context whatsoever, including the organization. What these three liked about work was that they could 'pull sickies' or come to work with hangovers. One had plans for the future and was using his job to fund these, but the other two had no apparent aspirations Although we only had three such respondents in our dataset, managers at the feedback workshop suggested that they were not unique, and like us, they contrasted these young men's apparent sense of alienation with their much more aspirational, energetic and socially embedded Indian counterparts.

Crucially, this notion that Indian and UK employees embraced very different work ethics, rooted in different social experiences and contexts, had significant consequences for organizational practices. In our data it was seen as unproblematic that, because of Indians' 'different' work ethic it was appropriate for them to take on 
activities and work to schedules that were deemed unacceptable to their British colleagues. From another perspective, of course, it could be argued that this cultural explanation was being used as a justification for exploitation. This is a vivid illustration of Gopal, Willis and Gopal's (2003) point about the conditioning effects of colonial practices noted above, whereby certain sets of arrangements come to be experienced as commonsense. However, it must be noted that not all the Indian employees simply accepted such practices as natural or inevitable. In other words, acceptance of these arrangements was not necessarily a subordination response. On the contrary, many Indian employees felt that they had something real to gain in taking on these extra responsibilities, working harder and demonstrating greater commitment than their UK colleagues, and that there were historical and material reasons for this difference in perception. In the words of one respondent:

I think that because we have a scarcity of everything except population, of course, material scarcity and everything, we want that much more to happen in our lives... And that material abundance there, because you have everything over there available, and you have loan and security systems and social systems and all these systems kicking in, then you don't really feel the need to manage your sense of security in the UK. Whereas here I have to manage that sense of security for myself.

This respondent, like others, saw himself as part of a rapidly changing Indian economy, an economy that brings with it significant opportunities and rewards for those who actively pursue them. Although an earlier quote suggested that Indians are happy to 'stretch' their hours because they love work, the image conveyed here is very different. According to this respondent, Indians are working in particular ways because in their society there is no safety net. From these data, it might be argued that the organization is taking advantage of this feature to make their Indian employees work more than their UK counterparts. However, described as a 'superior work ethic', and an example of 'cultural difference', such practices are seen as legitimate. Here again we take note once again of the interplay between organizational and individual attributions such that the organization is constructed as simply responding to the 'different' characteristics of the Indian workers, rather than being seen as exploitative, using its power to impose a more rigid set of practices on harder working and more compliant Indian employees.

\section{Competence}

Underpinning our analysis of the 'cultural difference' discourse thus far (and the data upon which it is based) is a dichotomisation of the UK and India. This was likewise apparent in respondents' discussions of competence. Although Indian representatives were generally far better educated than their UK counterparts, there was a feeling in much of the UK data that the Indians were 'really nice' and 'so willing', but lacking in competence. This tendency for UK employees to infantilize their Indian counterparts is illustrated in the following quotes, from respondents in all three UK centres:

In Mumbai they're very sort of professional, but when we, if we have to ring them or we get hold of them, you know, as if we still don't believe they know what they're talking about. You just don't have the confidence that they know it.

They're very keen to please, but when it comes to actually doing, it doesn't necessarily happen. 
Mumbai? As much as I don't like to say it, but they're quite annoying. They're just constantly messing things up and stuff. I have spoken to a few people, I mean they do try very hard.

Here and elsewhere in the data Mumbai colleagues are described rather like children, thus reinforcing the feeling noted by a respondent cited earlier, of UK superiority, and resulting Indian subordination. This is further illustrated in the extract below, where a Scottish manager describes the need to closely monitor the Indians' work:

You have to keep at them all the time to make sure they do what you're expecting. Once it's ingrained into them, 'you've got to do this and you've got to do it forever until I say you don't do it anymore', then once that's in, it's fine, but I think if you take your eye off the ball then things slip up a wee bit and they go back to whatever the old way was of doing things.

One of these routines was re-directing calls from independent financial advisors back to the UK, a policy which was developed as a response to advisors' hostility to the Mumbai operation. However, it appeared that although they were habitually told not to, sometimes Indian employees broke the rules and took the calls themselves. The whole issue of resistance is important, and merits further consideration. However, given our concerns here, we have chosen the quote to illustrate the ways in which the British habitually infantilise their Indian colleagues, and question their competence. As the discussion continued, the respondent explained that talking to IFAs was a complex matter that required further training. Her response to a question about providing this was:

Well, we're running a pilot to train up some of the higher skilled people to see if they're capable of doing it. I mean they probably think that we just want to give them easy work and keep all the complicated stuff here.

This IFA issue sheds light not only on the ways in which employees rhetorically constructed and positioned themselves and one another, but also on the material consequences of these understandings in terms of organizational policy and practice. Notably, some UK managers and many Indian respondents had some awareness of this political manoeuvring and, more insidiously, knew that the Indian operation was often used as a scapegoat. This was illustrated vividly during one of our visits to the Mumbai site. Preparing for the seminar described above, we arrived at the office one day to find the senior managers in a state of high anxiety because the entire telephone system in the Mumbai site had gone down, with all calls being diverted to the UK. This was causing tension, anger and confusion amongst British colleagues who had to manage the huge increase in call volume at the end of their shift. Although the problem was the introduction of a new telephone system in the UK, India was being blamed - it was seen as yet another example of Indian incompetence. The Managing Director of the Indian operation did not appear to be at all surprised by this response, and knew that India would be held accountable for the telephone failure. When we asked him about attempts at 'damage limitation' he said that, as usual, he had sent emails out explaining the nature of the fault, but he expected that this would do nothing to challenge people's perceptions. It was quite simply a feature of the 'outsourcing space' that the Indians had to accept. In his eyes, all they could do was to work even harder and even better to prove their added value.

The following month, we had the opportunity to chat about this at the session with a Scottish manager: 
'Do they actually do [the work] well? I would say probably nine times out of ten yes, but the one time out of ten gets exposed right across the organization type thing, you know, and I think that's where it gets hard'.

In the feedback workshop held with managers we discussed this issue further. Participants talked about how India was often blamed for whatever went wrong, and used words like 'safety valve' and 'emotional release' to describe this function. They spoke of how right across the organization India was seen as a legitimate target. Whereas it would not have been appropriate to complain about their Northern Irish or English colleagues, it was perfectly acceptable to criticise Mumbai. Earlier we suggested that 'cultural difference' was used as a justification for seemingly unfair working arrangements. Likewise, using Mumbai as a safety value appeared to reduce tension amongst UK employees, and make them feel more positive about their own abilities and status. This seemed to be particularly important in light of the difference between UK and Indian employees' educational qualifications, the relative status of their work within their particular social contexts and the continued growth and success of the Mumbai operation.

Importantly, with regard to this issue of competence, the majority of Indian respondents did not accept the charge that they were in any way less able than their British colleagues. On the contrary, they discussed at some length the ways in which their own performance often far exceeded that of their UK counterparts:

I think the quality that we deliver on the phone is much, much superior to the quality they deliver. I'm sorry. When we went to the UK for the process migration we heard calls. Our process, you know, we deal with death and bereavement calls, and in a bereavement call you really, really have to be very polite, very sympathetic and so on and so forth, but when we heard the calls over there it was, there was no sympathy, there was nothing.

[India] does things better. There are times when we go out of the way to look at certain things, a certain case coming to a conclusion. The people in the UK would not do that. They just throw the case back at us and say, 'something's amiss here. Why don't you look at it?'.

\section{And from the Managing Director:}

I don't want to demean the quality that's there in the UK, it's just that there is the quality that is delivered here because the basic underlying qualification is different. Believe me, we hire only minimum graduates whereas in the UK that's not the case... so there is a difference in intellect and that shows in the quality of the work we do.

In spite of their confidence in their abilities, though, one respondent explained how they frequently had to disguise this if it was seen to undermine UK colleagues. In particular, he resented the way in which Indian managers ingratiated themselves with their UK counterparts, and recast UK failings as developmental opportunities for Indian staff:

Many a time it happens that we have a certain procedure or operation that may not be acceptable to the people in the UK. We disagree at times and we put forward our disagreements in front of them, but most of the time they don't listen. [he goes on to describe a complex process which ultimately it falls to a senior manager or director to make a judgement on] I have told my team leader and even my operations manager to, you know, fight these kind of 
things. Why do we take it ourselves? I don't know why. It beats me hollow as to why we have to take this on. But they say, you know, they say why don't we derive learning from it, and why don't we sharpen our processes... That's something which I asked them to fight for which unfortunately - they don't fight.

The sense that that Indian employees had to be very careful when questioning the work of their British colleagues is in stark contrast to the barrage of criticisms regularly and freely levelled against Mumbai - from UK employees at every level (with the exception of those with first hand experience of the Indian context). Underpinning these data, then, is a portrayal of the UK being in charge, with Mumbai depicted as a bright and friendly, but muddled, childlike subordinate in need of close monitoring and on-going control.

With respect to Gopal, Willis and Gopal's concept of 'conditioning effects' noted above, these are interesting, contradictory data. On one hand, in their accounts Indian respondents are standing up to the criticisms levelled against them, and thus do not appear to be conditioned in the way Gopal and his colleagues describe. They believe that they are competent, and in terms of their educational backgrounds and the quality of service they provide, see themselves as outpacing their British colleagues. However, when it comes to defending their positions in public, the data suggest far more reticence. Rather than insisting on what they think is right, this respondent suggests that Indian managers recommend what we have seen elsewhere in the data - that employees use the experience as an opportunity to demonstrate their commitment, effort and good will, thus retreating back into the familiar discourse of cultural difference and in so doing, reproducing its dominant subject positions and power relations.

\section{Discussion}

In this article we have examined how UK and Indian employees working in customer service centres in England, Scotland, Northern Ireland and Mumbai draw on discourses of culture and cultural difference to construct and position themselves in relation to one another. Through our extensive data analysis, the aim has to deepen existing understandings of individuals' lived experiences of these emerging forms of organization. Our findings lead to three broad contributions - the first is empirical, while the second and third are conceptual.

First, as discussed in our literature review offshoring sectors are in flux, with as yet little detailed examination of the implications of the diverse structural arrangements for individuals experiences of work in these putative settings (Taylor \& Bain, 2005; Walsh \& Deery, 2006). Focusing on three source country customer service centres and their 'captive' Indian unit, our findings have highlighted the complex networks of social relationships within which employees are operating, and the need to examine these as a central aspect of the research design. On an operational level, as a captive unit the Mumbai site was an integral part of the case study company. At the same time, though, our data reveal the profound differences between these four local contexts. In spite of the fact that respondents see themselves as being part of a shared organizational history and are answerable to the same organizational imperatives, they do some from very different vantage points, and thus the meanings they make and the actions they take can be widely divergent.

Scholars have noted their concerns about the impact of new forms of organizations, particularly BPOs, on Indian identities (Ramesh, 2004; McMillan, 2006). Our data do not support these findings. While there is clear evidence of Indian respondents negotiating pathways through diverse cultural prescriptions, we did not get a feeling 
that this organization was foisting a new, Western identity on employees, that was at odds with their lives outside of work, or of employees leading double lives. Our respondents discussed at some length the differences between working for a USoriented BPO, and a UK captive - noting not only obvious differences like timing of the working day, but also more subtle aspects to do with the historical relationship between India and the UK and its legacy. They also discussed the difference it made to work alongside UK colleagues, with a constant flow of staff between countries. We would argue that to begin to develop meaningful insights into the implications of new forms of organizing for cultural identity, a consideration of organizational context is crucial.

Our second contribution concerns the interplay between material circumstances and cultural explanations throughout our dataset, and the implications of this on-going dialogue for people's lived experience of work in this organization. Through our analysis we showed how ascriptions of cultural difference with respect to the language barrier, work ethics and organizational practices, and notions of competence were used to explain or justify particular organizational arrangements and patterns of behaviour. With respect to work ethics, for example, we argued that the attribution of cultural difference with respect to Indians' superior work ethic, provided a rationale for why Indian employees habitually worked over-time while the British did not, to justify giving Indian staff extra work, or to explain why the Mumbai site was frequently selected to pilot new training materials. On the other hand, the idea of Indians as incompetent was used as a justification for additional monitoring of Indian representatives, for limiting their discretion and more insidiously, for legitmating their use as a scapegoat when things went wrong.

In some ways, these polarities: us/them, competent/incompetent, adult/child could be seen as examples of Edward Said's (1978) concept of orientalism, central to which is the notion of East and West as cultural rather than material artefacts, and of the East as a construction of the West. In Said's words:

Since the middle of the $18^{\text {th }}$ century there had been two principal elements in the relation between East and West. ... The essential relationship, on political, cultural, and even religious grounds was seen - in the West, which is what concerns us here - to be one between a strong and a weak partner.

Many terms were used to express the relation... The Oriental is irrational, depraved, (fallen), childlike, 'different', thus the European is rational, virtuous, mature, 'normal'... Yet what gave the Oriental's world its intelligibility and identity was not the result of his own efforts but rather the whole complex series of knowledgeable manipulations by which the Orient was identified by the West (1978: 39-40).

Certainly there are elements, even in this short quotation, which appear to be echoed in our dataset: references to India as exotic, at once childlike and dangerous; and of the UK as powerful and in charge, though also frightened. While highly influential, Orientalism has been extensively criticized (Jasanoff, 2006), in part for what is seen as its reductive, dualistic perspective. While we accept this criticism and acknowledge the problems of dualistic analyses, we would argue that binary opposites remain a powerful framework through which individuals make sense of and account for their experiences (Duberley, Cohen \& Mallon, 2006), as evidenced in our respondents' accounts. Both McMillan and Ramesh argue that the introduction of the BPO sector in India, though its imposition of Western norms and values, is serving to destabilise Indian identities. Thus, central to both their analyses is a strong sense of East and West, of Us and Them. The case we are making here is different. Our data 
did not reveal this kind of cultural takeover. Rather, we are highlighting the use of these cultural ascriptions not as a window into respondents' feelings about cultural identity, but as rhetorical devices used to justify certain patterns of thought and behaviour. We found that attributing aspects of organizational life to cultural fact served to naturalise these patterns of thought and action such that they assumed a kind of inevitability, and thus were accepted without question as 'how things are'. In this sense they worked, as Barthes cultural mythologies (1973), to sustain existing arrangements, foreclosing discussion that could potentially disturb this (precarious) status quo. Here the idea of 'the language barrier' is a case in point, serving to raise the status of the UK employees 'authentic' usage in contrast to their Indian colleagues 'artificial' pretensions.

Here a few interesting issues arise. First, we noted that whilst these explanations were most widely used in the UK data, Indian employees nevertheless colluded in them. In this sense, these respondents could be seen as participating in the kind of invisibility and conditioning effects Gopal and his colleagues (2003) described as part and parcel of the process of colonialism (and its most recent expression in globalisation). Why they might do this is a vexing question which we can only answer in a speculative way. It could be that the Indian respondents genuinely believe that these processes are fair and appropriate. Indeed, several did suggest that as the newest recruits in an established UK company, their role was to fit in, do the job well, and not rock the boat. On the other hand, as suggested by other employees, it could be that people feel that they ultimately have something to gain by appearing to acquiesce at this stage. As noted, there was a strong sense amongst Indian respondents at all levels that the Indian employees had to prove themselves to their UK counterparts, and that once they did, they could begin to create opportunities for themselves. In this sense, conforming at this stage could be a strategy that Indians were deploying so as to reap greater career rewards in the future.

Notwithstanding their appropriation of the default cultural position (and the associated idea that Indians need to blend in to this UK-defined environment to be successful), there is nevertheless a strong sense of uncertainty in the UK data, and a concomitant self confidence in the Indian accounts, that we need to take seriously. Indeed, this ambivalence raises questions about Said's view of the West as inevitably assuming a position of strength. This creeping insecurity in the UK accounts could be partly a result of the increasing importance and steady growth of the Mumbai operation, and with this an awareness amongst British and Indian respondents that the majority of Indian employees have accrued valued career capital (lellatchitch, Mayrhofer \& Meyer, 2003) which could be valuable in an organization which prides itself on its transparent, meritocratic practices. Indeed, this sense of nervousness could help to explain the pervasive reliance on cultural justifications. On one hand, it could be argued that such ascriptions were disarming. That is, notions of Indians as friendly but incompetent could work to dispell the fear that Indian colleagues appeared to evoke amongst some of their UK colleagues. Alternatively, it could be that these cultural explanations served to shift the exercise of power from the corporate level (in the face of which employees felt impotent) to the individual whereby, through ascriptions of cultural difference, UK respondents could regain some sense of control. At the same time, by legitimating existing ways of thinking and acting, these rhetorical devices served to exclude the possibility of question or challenge, providing instead a fragile sense of security in a turbulent organizational environment.

Our third contribution relates to the issue of ambivalence noted above. Although many of our respondents mobilised notions of cultural difference to make sense of and justify how things were, there was at the same time significant contradiction within respondents' accounts, and ambiguity in how people were positioning 
themselves within their social networks. Regarding contradictions, while on one hand people used the kind of binarisms noted above in seemingly totalising ways, close analysis reveals that these ascriptions were actually full of inconsistencies. For example, reminiscent of Said's quote above, within the UK data Indians were constructed as both infantile and threatening. Likewise Indians spoke of their UK colleagues in a way that was at once deferential and patronizing. For example, many UK respondents expressed a certain confidence with respect to their seemingly superior linguistic skills or general competence vis-à-vis their Indian colleagues, but at the same time their fears about the potential threat posed by their educational backgrounds, their high levels of motivation and lofty career aspirations. Whilst of course it is not surprising to find this kind of contradiction in qualitative accounts, such examples do warn us against reductionist explanations.

On a more abstract level, the mobilisation of the kind of inconsistencies noted above points to what Bhabha sees as the destabilisation of boundaries between the self and other. While Said hints at these lines of fracture and discontinuity, in The Location of Culture (1994) Bhabha develops these ideas in his concepts of fixity and ambivalence:

An important feature of colonial discourse is its dependence on the concept of 'fixity' in the ideological construction of otherness. Fixity...is a paradoxical mode of representation: it connotes rigidity and an unchanging order as well as disorder, degeneracy and daemonic repetition. Likewise the stereotype, which is its major discursive strategy, is a form of knowledge and identification that vacillates between what is always 'in place', already known, and something that must be anxiously repeated... It is the force of ambivalence that gives the colonial stereotype its currency (1994: 95).

For our purposes, the important points here are Bhabha's emphasis on the precariousness of order, the need for repetition, and the possibility of resistance. In the section on competence we discussed the Scottish manager's view that Indian representatives needed to be constantly reminded of the right way to do things. In Bhabha's terms, these on-going reminders might also serve to fix this idea of Indian incompetence in the minds of staff. Indeed, throughout the data we have examples of such reminders, all of which could be seen as illustrating the fragility of the existing order, and the continual repetition of certain cultural rituals (like forbidding Indian representatives from speaking to Independent Financial Advisors, Indian managers not allowing their subordinates to question UK judgement, etc.) to keep it intact.

Regarding resistance, the data on language and the Indian respondents' desire to perfect their language skills provide some interesting food for thought. As noted in that section, it could be of course that this ambition to speak the perfect English is something which is embedded in the educational system that staff members participated in for many years, and is likewise expressed in wider cultural artefacts such as the prolific English language media and India's huge English language publishing industry. In this sense, it is an aspiration that employees bring to the organization from outside, and is fuelled by the organization's performance criteria. On the other hand, it could also be related to the widespread feeling amongst Indian staff that they had to perform at the highest possible levels to achieve credibility and recognition in this UK dominated organizational environment. However, taking account of Bhabha's work on mimicry, an alternative interpretation is that there is a certain irony, and with it a certain sense of resistance, implicit in this desire to 'blend in'. Bhabha suggests that 
mimicry represents ironic compromise... Which is to say, that the discourse of mimicry is constructed around an ambivalence; in order to be effective, mimicry must continually produce its slippage, its excess, its difference... The effect of mimicry on the authority of colonial discourse is profound and disturbing (1994: 122-123).

Indeed, several of our UK respondents expressed their unease not only with what they saw as some of their Indian colleagues' excessive desire to perfect their English, but with the results of these efforts, described by some as 'strange' and 'artificial'. There are likewise examples of Indian staff taking on aspects of the cultural training, in particular with regard to their handling some of the company's older customers, in ways that their UK colleagues find odd. UK staff spoke of these behaviours as disturbing because they were at once very familiar, and the same time exotic and different. Most intriguing about these instances was that UK respondents could not pinpoint the problem. All they could really talk about was their sense of discomfort. For their part, discussing these aspects of their work, Indian respondents talked above all about following the rules, conforming to company expectations, and performing to the best of their ability. Whilst there is not scope within this paper to further develop ideas about irony, mimicry and resistance, we feel that it is an area which merits further investigation.

Focusing on the ways in which UK and Indian respondents in this financial services organization construct themselves and one another, our analysis reveals above all paradox and ambivalence. On one hand it demonstrates respondents' use of binary understandings: the Indians and the British; their work ethic and ours; competence and incompetence, to justify particular patterns of thinking and acting, and ultimately to legitimate the persistence of existing arrangements. However, at the same time it highlights a deep sense of contradiction and doubt that underpins these dichotomies: expressed as inconsistencies within these prescriptions, as rules and patterns of thought and behaviour which are reiterated on a daily basis, and as ironic conformity. We would argue that this ambivalence can be seen to elucidate the fragility of the existing order, the possibility of resistance and potentially of change.

\section{References}

Barthes, R. Mythologies. London: Palladin, 1973.

Batt, R. and Moynihan, L. The viability of alternative call centre production models. Human Resource Management Journal, 2002, 12, 4,14-34.

Bhabha, H. The location of culture. London and New York: Routledge, 1994.

Bryman, A. Social research methods. Oxford: Oxford University Press, 2004. Cohen, L. and Mallon, M. "My brilliant career?" Using stories as a methodological tool in careers research. International Studies of Management and Organization, 2001, $31,3,48-68$.

Chakrabarty, D. Legacies of Bandung: decolonialisation and the politics of culture. Economic and Political Weekly, 2005, November 12 (http://www.epw.org.in)

Deb, S. Call Me. Guardian Weekend, 2004, April 3: 14-23.

Dossani, R. and Kenney, M. Went for cost, stayed for quality? Moving the back office to India. Asia Pacific Research Centre Working Paper, Stanford, CA, USA.

(http://APARC.stanford.edu), 2003. 
Duberley, J., Cohen, L. and Mallon, M. Constructing scientific careers: change, continuity and context. Organization Studies, 2006, 27,8, 1131-1151.

Frenkel, S., Korczynski, M., Shire, K. and Tam, M. On the front line. Organisation of work in the information economy. USA: ILR and Cornell University Press, 1999.

Friedman, T. The world is flat. The globalized world in the $21^{\text {st }}$ century. New York: Penguin Books, 2005.

Gopal, A., Willis, R. and Gopal, Y. From the colonial enterprise to enterprise systems: parallels between colonization and globalization. In A. Prasad (Ed.) Postcolonial theory and organizational analysis. London: Palgrave, 2003, 233-254.

Gramsci, A. Selections from the prison notebooks. (Q. Hoare and G. Nowell-Smith, Trans). London: Lawrence and Wishart, 1971.

Hammersley, M. and Atkinson, P. Ethnography: principles in practice, $2^{\text {nd }}$ edition. London: Routledge, 1995.

Houlihan, M. Tensions and variations in call centre management strategies. Human Resource Management Journal, 2002, 12, 2, 67-85.

lellatchitch, A., Mayrhofer, W., and Meyer, M. Career fields: a small step towards a grand career theory? International Journal of Human Resource Management, 2003, $14,5,728-750$.

Jasanoff, M. Before and after Said. London Review of Books, 2006, 28,11, 8 June. (http://www.Irb.co.uk).

King, N. Using interviews in qualitative research, in C. Cassell and G. Symon (Eds.) Essential guide to qualitative methods in organizational research, London: Sage, 2004, 11-22.

Kinnie,N., Purcell, J. and Hutchinson, S. "Fun and surveillance": the parodox of high commmitment management in call centres. International Journal of Human Resource Management, 2000, 11,5, 967-985.

Korczynski, M. The contradictions of service work: call centre as customer oriented bureaucracy', in A. Sturdy, I. Grugulis and H. Willmott (Eds.) Customer service: empowerment and entrapment (critical perspectives on work and organizations). London: Palgrave, 2002.

Kvale, S. InterViews. London: Sage, 1996.

Macaulay, T.B. A minute on Indian education. In T.B. Macaulay, Selected writings Chicago: The University of Chicago Press, 1972, 237-251.

McMillan, Divya Outsourcing Identities. Call centres and cultural transformation in India. Economic and Political Weekly, 2006, January $21^{\text {st }}, 235-241$

(http://www.epw.org.in).

Mirchandani, K. Practices of global capital: gaps, cracks and ironies in transnational call centres in India. Global Networks, 4,4, 2004, 355-373. 
Mirchandani, K. Webs of resistance in transnational call centres. Strategic agents, service providers and customers. In R. Thomas, A. Mills and J. Helms Mills (Eds.) Identity politics at work: resisting gender, gendering resistance. London: Routledge, 2005,179-195.

Mishra, P.Temptations of the West. How to be modern in India, Pakistan and beyond. London: Picador, 2006.

Mitter, S. Teleworking and teletrade in India. Combining diverse perspectives and visions. Economic and Political Weekly, 2000, June 24: 2241-2252

(http://www.epw.org.in).

National Association of Software and Service Companies (NASSCOM) (2006) http://www.nasscom.in.

Ramesh, B. "Cyber Coolies" in BPO. Insecurities and vulnerabilities of non-standard work. Economic and Political Weekly, 2004, January 31 (http://www.epw.org.in).

Said, E. Orientalism. London: Penguin Books, 1978.

Schiller, $\mathrm{H}$. Not yet the post-imperialist era. Critical Studies in Mass Communication, 1991, 8, 13-28.

Taylor, P. and Bain, P. Call centres in Scotland and outsourced competition from India. Stirling: Scotecon, 2003.

Taylor, P. and Bain, P. "India calling to far away towns": the call centre labour process and globalisation. Work, Employment and Society, 2005, 19, 2, 261-282.

Ullrich, O. Technology. In W. Sachs (Ed.) The development dictionary: a guide to knowledge as power. London: Zed Books, 1992, 275-287.

Walsh, J. and Deery, S. Refashioning organizational boundaries: outsourcing customer service work. Journal of Management Studies, 2006, 43,4, 557-582.

We would like to thank Peter Ackers, Ravishankar M. N., three anonymous reviewers and Paul Edwards for their thoughtful and thought-provoking comments on an earlier version of this paper and for their valuable guidance on its development. 